\title{
DELEGATING RECRUITMENT UNDER ASYMMETRIC INFORMATION
}

\author{
SARBAJIT SENGUPTA
}

\author{
CESIFo WORKING PAPER NO. 810 \\ CATEGORY 4: LABOUR MARKETS \\ DECEMBER 2002
}

Presented at CESifo Venice Summer Institute, July 2002

\footnotetext{
An electronic version of the paper may be downloaded

- from the SSRN website: www.SSRN.com

- from the CESifo website: www.CESifo.de
} 


\title{
DELEGATING RECRUITMENT UNDER ASYMMETRIC INFORMATION
}

\begin{abstract}
Recruitment is often delegated to senior employees. Delegated recruitment, however, is vulnerable to moral hazard because senior employees may avoid recruiting the best candidates who could threaten their future seniority. We find that seniors will not deliberately choose bad candidates if the only information asymmetry between the owner and the recruiter relates to the candidates' 'type'. Delegation is then superior to direct (owner) recruitment and offering 'tenure' or guaranteed seniority to the senior employee is neither always desirable for the owner nor necessary to ensure good recruitment. If there is information asymmetry between the owner and the senior employee regarding additional aspects of firm operations, however, moral hazard may exist and tenure may be needed to ensure that the best candidate is selected. Offering tenure may then be desirable for the owner.
\end{abstract}

JEL Classification: D23, D82, J41, L22.

Keywords: recruitment, delegation, moral hazard, long term contract.

\author{
Sarbajit Sengupta \\ Visva Bharati University \\ Abanpalli \\ Santiniketan \\ West Bengal 731235 \\ INDIA \\ ssengupt@usc.edu
}




\section{Introduction}

Recruiting competent employees is of paramount importance to any business firm. As the firm can rarely observe the ability of a job applicant, the recruitment process is vulnerable to the well known problems of transaction under asymmetric information. It is therefore not surprising to find that many of the key models of asymmetric information - particularly those involving signaling and screening - were originally framed in the context of this problem (Spence, 1973).

In practice, firms use a wide variety of methods to recruit new employees. This ranges from specialized personnel or human resource divisions for large business corporations to interviews conducted by line managers and owners (Stewart and Knowles, 2000) or even informal 'word of mouth' referrals from senior employees in case of small business firms (Caroll, Marchington, Earnshaw and Taylor, 1999).

An important feature common to many of these methods is the delegation of the responsibility of recruitment by the owner to personnel departments, 'line managers', senior employees or specialized employment agents. Presumably this is due to the better information or ability of such agents to identify job applicants compared to the owners - i.e. partners or shareholders in the firm (Greenwald ,1986 Williamson,Wachter and Harris,1975)

Designing optimal contracts to delegate tasks to a privately informed agent is one of the classic problems of mechanism design (Guesnerie and Laffont, 1979). The problem arises due to the divergence of interests between the principal and the agent. In the present context, senior employees entrusted with recruitment may avoid hiring the best candidates who may threaten their own position in the organizational hierarchy (Carmichael, 
1988, Friebel and Raith, 2000).

In this paper we explicitly formulate the owner's problem of choice between direct recruitment and delegation. In other words the owner must decide whether to delegate to the senior (supervisory) personnel the task of hiring new employees or take an active role herself - assuming that she is not busy elsewhere'(Itoh, 1994) . In doing this, she has to trade off the gains from superior competence/information of the supervisor against losses from opportunism on his part ${ }^{1}$.

Looked at this way, it might appear that our formulation is relevant only in the context of reasonably small proprietorships or partnerships, since the shareholders or the real owners in large and well diversified corporations are unlikely to have any say in the recruitment process. This, however, overlooks the fact that many firms in Asian, Latin American and other developing countries are controlled by tightly knit 'family business groups'(Ghemwat and Khanna, 1998). Further, even in large US or European corporations, individuals or small groups with sizable shareholding often wield enough control for our analysis to be relevant.

Differences in the organizational status of the (internal) recruiting agents in 'large' and 'small' firms often go hand in hand with differences in the nature of information asymmetry that are crucial in determining the choice between direct recruitment and delegation. Specifically, personnel departments in large firms are concerned mainly with hiring and are unlikely to hold other 'specialized business information' relative to the owner(s). The line manager or senior employee in a small business, on the other hand, typically holds private information in other aspects of business in addition

\footnotetext{
${ }^{1}$ This is similar to the idea that transfer of real authority to the agent promotes agent's initiative (to acquire information) but results in a loss of control for the principal (Aghion and Tirole, 1997).
} 
to his special knowledge regarding candidates. We find that the problem of moral hazard - deliberately choosing bad candidates to ensure ones seniority in the organizational hierarchy - appears on the latter scenario.

Our study is also connected to the literature on tenure (Carmichael, 1988) where it is assumed that (a) the current faculty in an university can better evaluate new candidates than the university administration and (b) there is some constraint on the number of faculty positions. It then turns out that the current faculty must be assured of their jobs - through tenure in order to honestly evaluate the candidates In this paper our principal focus is on the choice between direct recruitment and delegation. Hence, to start with we assume that tenure is not an option - i.e. the owner cannot credibly commit to preserving the seniority of the supervisory employee in order to ensure that he doesn't deliberately choose an incapable candidate. Later, though, we examine whether it is worthwhile to provide the supervisor with tenured contracts that assures his position and thereby removes any moral hazard in the recruitment process.

We find that if the only information asymmetry between the owner and the senior employee is the one regarding the ability of the potential candidates, the latter never deliberately chooses an inferior candidate although he has an incentive to conceal the candidate's ability after recruitment. Under these conditions the owner always prefers to delegate recruitment to the senior employee. However, this also means that tenured contracts are not necessary to mitigate moral hazard on the part of the senior employee. In fact, we find that untenured short term contracts may often be preferable to tenured contracts under these circumstances.

On the other hand, if there is an additional information asymmetry regarding some periodwise independent decision parameter, then there is a 
scope for second period 'information rents' that act as an incentive to retain seniority by deliberately choosing an inferior candidate. The owner may then prefer to recruit directly (i.e., by herself) in the absence of the 'tenure' option. If she can offer tenure, however, delegation will always do better than direct recruitment.

The paper is organized as follows. Section 2 describes case of asymmetric information in a single dimension, i.e., the ability of the candidate. Sections 3 considers the case of additional asymmetry in information. Section 4 briefly considers tenure. Section 5 concludes.

\section{Information Asymmetry in candidates' ability}

\subsection{Model}

In the formal model we have one principal - the proprietor, partner or the 'controlling group' and one agent - the senior employee, experienced line manager or the 'human resource department. There is exactly one vacancy and two applicants for the post - although this last feature may be easily generalized. We start with the setting where the senior employee's private information regarding the candidate's ability is the only source of information asymmetry between him and the owner. The model makes the following assumptions.

Assumption 1: Supervisors/ managers have a greater impact on productivity than lower level workers.

As already indicated, this is because managers are usually entrusted with the independent responsibility of making critical decisions that affect firm profitability or firm value while ordinary workers/laborers are usually relegated to performing routine tasks. Thus, the owner prefers more productive people at the managerial positions [see Milgrom and Roberts (1994)]. 
Thus, we assume the production function of the firm in period t to be:

$$
Y_{t}=m_{t}\left(e_{t}+l_{t}\right)
$$

where $Y_{t}$ is the output of the firm in period $t, m_{t}$ and $l_{t}$ are the abilities of the manager and ordinary worker/laborer in period t respectively, $e_{t}(>1)$ is the effort of the manager in period $t$. The absence of a effort term for the laborer indicates the routine nature of the job where only the basic ability contributes to the productivity of the firm while for the manager the effort also matters.

Assumption 2 We assume, for the sake of simplicity that potential candidates are of two types : 'bad types' with ability $n_{B}$ occuring with probability $p$ and 'good types' with ability $n_{G}>n_{B}$ occuring with probability $(1-p)$. At the time of recruitment, the senior employee is assumed to observe the type of the two available candidates while the owner only knows the probability distribution referred to above. This is likely to be true where the senior employee - who is also the supervisor/manager in period 1 - is more informed or more involved in the operational activities of the firm or has superior professional competence. The competence of the senior employee, $s$, on the other hand, is assumed to be common knowledge.Further, we assume that :

$$
n_{G}>s>n_{B}
$$

so that the ability of the senior employee is lower than the good type candidate but higher than the bad type. Hence, in terms of our framework, if the owner learns that the new employee is 'good' (or at least if the 'expected type' is $>s$ ) she would promote her to the supervisory/managerial position. 
We assume that the senior employee is not fired but relegated to the position of the ordinary worker.

Assumption 3: There are benefits attached to managerial positions that motivates employees to strive for/retain such positions.In our model, this is the result of greater discretion in managerial positions that entitle the supervisor/managers to information rents in arising out of private information. In particular, it is assumed that the utility function of the employees is

$$
U_{t}=U\left(w_{t}, e_{t}\right)=w_{t}-V\left(e_{t}\right)=w_{t}-e_{t}^{2}
$$

Thus, the utility function of the employees are separable in income (wages) and effort. It is assumed that the opportunity costs of employees are independent of their abilities. For those working as laborers, therefore, we simply have $w_{j}^{*}=0$. Further, under perfect information, the wages of the managers/supervisors exactly compensates for their effort, $e^{*}$, which is optimally chosen by the owner, i.e., $w_{s}^{*}=e^{* 2}$. Thus, under perfect information there is no reason for the employee to strive for promotion to managerial positions. However, the situation changes once we introduce asymmetric information and the manager has to be given information rent to prevent opportunistic behaviour. This implies that $w^{s *}>e^{* 2}$ so that mangerial positions become desirable.

The time structure of the game is as follows:

\section{Fig 1: Time Structure - private information on 'type' of recruit}

In this structure, the the senior may retain his seniority either by deliberately choosing a 'bad' candidate when a good one is available or by 
concealing the true type of the candidate. It is therefore important to look at the expected profits of the owner not only under the usual (second - best) separating contract but also the pooling contract - since there are now additional incentives on the part of the senior employee to conceal the type of the candidate - aside from obtaining immediate information rents..

Consider 1 period post recruitment profits of the employer. Let $\widehat{\Pi}(\beta)$ and $\bar{\Pi}(\beta)$ be the one period expected profits of the owner respectively under contracts that are separating and pooling in the candidate type that is privately known to the owner. This is clearly a function of $\beta$, the probability that the candidate has a 'bad' type - a factor that depends on the mode of recruitment.Then it can be shown that (appendix):

Lemma 1: $(i)$

$$
\frac{d \widehat{\Pi}}{d \beta}<0, \frac{d \bar{\Pi}}{d \beta}=0
$$

and

$$
\widehat{\Pi}(\beta)>\bar{\Pi}(\beta)
$$

Part (i) simply states that higher the probability that the recruited candidate has a 'bad' type, lower are the expected one period profits of the owner under a separating contract, although under a pooling contract the one period expected profit is not sensitive to the distribution of types. Intuitively, the only pooling contract acceptable to both types in this framework is one that gives zero profit to the'bad' type. Since this is the only contract that is offered (and accepted by the senior) irrespective of the actual type of the recruit, the output and payment of the owner and hence her expected profits are always the same. In a separating contract the owner obtains a higher ouput and profits despite paying information rents when the senior 
'reveals' the candidate to be 'good', hence her expected profits are a decreasing function of $\beta$. Part (ii) implies that this higher profit obtained in a separate contract in case the candidate is good also accounts for the owner's profit to be higher than in a pooling contract.

\subsection{Dynamic Contracts without commitment}

Suppose now that the owner cannot credibly commit to the senior employee that he will not be superceded if the new recruit is found to be more competent than he is. Thus if the senior employee honestly chooses the best available candidate and exerts the corresponding level of effort in period 1 then it is quite likely that he may be superceded. This leads to a clear incentive to conceal the candidate's type by lowering his own (unobservable) effort.

The literature on dynamic adverse selection models [Laffont and Tirole $(1987,1988)]$ considers situations when the types are perfectly correlated accross periods and it is not possible for the principal to commit not to take advantage of the information revealed in the first period game. In this case (provided $\partial$ is high enough) a separating contract in the first period is not feasible since the good type would demand additional rents to compensate for their lost information rents in period 2. It is shown then the optimal solution in that case is the static pooling contract in period 1 followed by the static separating contract in period $2 .^{2}$

The first point is that in such a contract, the senior employee can make any information rents at all only if he has chosen a 'good' candidate. With

\footnotetext{
${ }^{2}$ For this result, see Proposition 2 in Laffont and Tirole (1987). The intuition is that for a large $\delta$ the agent is more sensitive to the loss of second period information rents due to first period revelation. To induce him to reveal him in period 1 is very costly and a pooling contract is prefereable.
} 
a 'bad' candidate he earns no information rent in either period. Hence we have:

Lemma 2: When the only asymmetric information is regarding the type of the candidate there does not exist any moral hazard, i.e., the senior employee never deliberately chooses a bad candidate when a good one is available.

The second important issue is that, unlike the standard Laffont Tirole model, a pooling contract in period 1 leads to the replacement of the senior employee if the expected type of the new recruit is better than the candidate, i.e., $E(n)>s$. This is particularly important in the case of delegation since the senior's preference for a good type (if at least one is available) implies that the expected type of candidate improves following recruitment. The senior employee then loses nothing by accepting a separating contract in the first period itself.

Proposition 1 If the only asymmetric information is about the candidate type the optimal contract is:

1. pooling in the first period if the expected post-recruitment type of the recruit is worse than the senior employee $E(n)<s$ and the senior employee always retains his seniority.

2. Otherwise, ie, if $E(n)>s$, the first period contract is separating and the senior employee loses his seniority if the new candidate turns out to be more efficient. The period 2 contract is fully separating.

3. Further, the owner always prefers to delegate recruitment.

Proof: Check that under direct(owner) recruitment, the probability that the candidate chosen is bad (resp. good) will be $p($ resp. $(1-p))$, since 
the owner cannot observe the type of the candidate. In other words $\beta=p$. Under delegation, the senior employee obtains an information rent only if the employee is 'good' and chooses a 'good' one whenever available. He chooses a bad candidate only when both are bad, i.e., $\beta=p^{2}$.Otherwise, i.e., with probability $1-p^{2}$, he chooses a good candidate.

Thus, when the owner carries out recruitment, the expected post recruitment type of the candidate is $E(n)=\bar{n}=p n_{B}+(1-p) n_{G}$. Hence, if $s \geq \bar{n}$, a pooling equilibrium in period 1 would lead to the senior employee retaining his position. This is exactly similar to the situation in Laffont and Tirole (1987). Consequently if the owner offers (a pair of) short term contracts, it would consist of the optimal static pooling contract in period 1 and the optimal separating contract in period 2. However, if $s \leq \bar{n}$, a pooling contract in period one would lead to the senior losing his job at the end of the first period as the expected type of the new recruit is higher than his own. In this case, therefore he has no reason to reject the optimal separating contract if it is offered by the owner in period 1 (which gives him at least the information rent that he would get by concealing his type).

Now consider delegation.Here, since in the absence of moral hazard (lemma), the senior employee always chooses a good candidate (if available) the expected type of the candidate is $\widetilde{n}=p^{2} n_{B}+\left(1-p^{2}\right) n_{G}>\bar{n}$. This means the likelyhood that the expected type of the candidate is greater than the senior employee is even higher - an event clearly more attractive to the owner.

Comparing the direct and delegated contracts we find that, when $s>$ $\widetilde{n}>\bar{n}$, so that the period 1 contract is a pooling contract clearly $\bar{\Pi}\left(p^{2}\right)+$ $\partial \widehat{\Pi}\left(p^{2}\right)>\bar{\Pi}(p)+\partial \widehat{\Pi}(p)$ and delegation is always superior. Second when $\widetilde{n}>\bar{n}>s, \widehat{\Pi}\left(p^{2}\right)+\partial \Pi^{*}>\widehat{\Pi}(p)+\partial \Pi^{*}$ and again delegation dominates 
direct recruitment. Finally, check that when $\widetilde{n}>s>\bar{n}, \quad \widehat{\Pi}\left(p^{2}\right)+\partial \Pi^{*}>$ $\bar{\Pi}(p)+\partial \widehat{\Pi}(p)$.

\section{Additional Asymmetry in Information}

A typical feature of small firms is that the senior employee who acts as the manager in period 1 often has responsibilities other than recruitment. The senior employee or even 'line managers' in small and medium enterprises may be involved in input purchase and product pricing or marketing decisions or even investment and financial decisions. Clearly, accurate decision making in these areas may involve access to private information regarding various aspects of firm activities - input and output price movements, material inventories, purchase orders, state of machinery and equipment etc. And these often entitle him to information rents in addition to those related to the cadidate 'type'. This is, of course, much less true of the 'human resource manager' in the large and diversified corporation who is concerned exclusively with recruitment and other aspects of employee welfare.

We shall assume (1) that the manager's access to this additional level of private information is characterized by his observation of the true realization of a periodwise uncorrelated random parameter $z_{t}$ in each period, (2) this realization of $z_{t}$ is not in any way correlated to the ability of the recruit $n$.Thus, we assume the production function of the firm in period t to be :

$$
Y_{t}=m_{t}\left(e_{t}+l_{t}+z_{t}\right)
$$

where $z_{t}$ is the realization of the random parameter in period $t$. We assume that in any period $t, z_{t}$ may take a value $L$ (low) with probability $q$ or $H$ (high) with the complementary probability $1-q$. The modified time structure of the game is as follows: 


\section{Figure 2: Time Structure with additional asymmetry}

As before, the senior may retain his seniority either by deliberately choosing a 'bad' candidate or by concealing the candidate's type . Note however, that the senior employee now has private information regarding both $n$ and $z{ }^{3}$ The differences between these two dimensions of information asymmetry are that (i) while $n$, the candidate type, once chosen, remains unaltered across periods, $z_{t}$ is a periodwise independent random parameter that is known only at the beginning of period $t$. (ii) while senior employee has incentives to conceal $z_{t}$ just to earn (period specific) information rents, he has additional incentives to conceal $n$ to retain his own seniority. So, in this case, we will need look at the expected profits of the owner not only under the second best contract fully separating in $n$ and $z$ contract along with the pooling-cum-separating contract -that is pooling in $n$ but separating in $z$.

Thus let $\widehat{\widehat{\Pi}}(\beta)$ and $\overline{\bar{\Pi}}(\beta)$ be the one period expected (post recruitment) profits of the owner respectively under fully separating and the pooling-cumseparating contracts - which as before are dependent on $\beta$, the probability that the candidate has a 'bad' type. (appendix):

Lemma 3: $(i)$

$$
\frac{d \widehat{\widehat{\Pi}}}{d \beta}<0, \frac{d \overline{\bar{\Pi}}}{d \beta}=0
$$

and

$$
\widehat{\widehat{\Pi}}(\beta)>\overline{\bar{\Pi}}(\beta)
$$

\footnotetext{
${ }^{3}$ In general, multidimensional contract menus are quite complex (see for example Armstrong and Rochet, 1999). They are, however, relatively simpler in our case because the relevant parameters, $n$ and $z$, are completely independent of each other.
} 
The interpretation is similar to Lemma 1. The probability that the candidate has 'bad' type does not affect the expected one period profits of the owner if the contract is pooling in type (pooling separating contract) but affects it (adversely) if it is separating in type (fully separating contract). Part (ii) implies that the owner's profit in a fully separating contract is higher than in a pooling-separating contract.

\subsection{Dynamic Contracts: Moral Hazard in Recruitment}

In this setting, the senior employee can earn information rents from his private information regarding $z$ in addition to the information rents on type. By deliberately choosing a bad candidate, he loses his current information rents on $n$ but may retain his senior position that entitles him to positive information rents on $z$ in period 2. This, then, introduces the possibility of moral hazard on the part of the senior employee regarding recruitment, i.e.,of deliberately choosing a 'bad' candidate when a 'good' one is available. Specifically, we have:

Proposition 2 When there exists asymmetric information regarding both the candidate type and the periodwise independent random parameter:

1. T he owner offers a pooling - separating contract in period 1 if $s>\bar{n}=p n_{B}+(1-p) n_{G}$ when she recruits directly or if $s>\vec{n}$ $=p^{2} n_{B}+\left(1-p^{2}\right) n_{G}$ when she delegates. The senior chooses the best available candidate and always retains his position. If $s>\vec{n}>\bar{n}$, then delegation is preferred 
2. By contrast, if $s<\bar{n}$ under direct recruitment or if $s<\underline{n}$ under delegation she offers a fully separating contract in period 1 and the more capable employee is put in charge in period 2. The senior chooses the best available candidate. If $s<\underline{n}<\bar{n}$, then delegation is preferred.

3. Finally, if $\vec{n}>s>\underline{n}$ there may exist moral hazard under direct recruitment in the sense that the senior deliberately chooses a bad candidate when a good one is available. Direct recruitment then may be preferred by the owner to delegation.

Proof: Under direct recruitment the question of moral hazard in recruitment clearly does not arise. The expected type of the candidate is $\bar{n}=p n_{B}+(1-p) n_{G}$. If the type of the senior employee is higher, or $s \geq \bar{n}$, then by underreporting the 'type' of a 'good' recruit (by reducing his own effort ) he retains his seniority and obtains positive expected rents in period 1. Thus the period 1 equilibrium in this case is 'pooling-separating' and the senior employee retains his position. The period 2 equilibrium is of course fully separating.

For a similar equilibrium to hold under delegation, the senior's type must be higher than the (owner's) expected type of the recruit when the senior himself chooses a 'good' candidate if at least one is available, $s>\vec{n}=$ $p^{2} n_{B}+\left(1-p^{2}\right) n_{G}>\bar{n}$. Only then does the owner retain the senior following a period 1 pooling-separating equilibrium. When this last condition is satisfied therefore, there is a 'pooling-separating' equilibrium in period 1 and a fully separating equilibrium in period 2 under both direct and delegated recruitment.Delegation is preferred because a 'good' recruit is selected with a higher probability and this positively affects the second period (but not the first period) profit of the owner. This may be verified by checking that: 


$$
\begin{aligned}
& \frac{d \overbrace{\Pi}}{d \beta}=\overbrace{\text { where }} \overbrace{\Pi \text { is defined as the aggregate (two period) profits when } s>\vec{n}}^{d \beta}+\partial \frac{d \widehat{\bar{\Pi}}_{2}(\beta)}{d \beta}=0+(0<)<0
\end{aligned}
$$

However, if $s<\bar{n}$, under direct recruitment the senior would be replaced in a pooling equilibium, so that he has no "future incentives" to undereport the type of the new recruit over and above that of obtaining the standard period 1 information rents. The period 1 equilibrium is then fully separating leading to the repacement of the senior employee when the recruit is 'good'.The same happens under delegation if the senior's ability is so low that he would be replaced after a "pooling - separating equilibrium in period 1 even if he did choose a 'bad' candidate whenever available, i.e., if $s<\underline{n}_{\rightarrow}=p(2-p) n_{B}+(1-p)^{2} n_{G}<\bar{n}$. Choosing a 'bad' recruit intentionally therefore makes no sense for the senior in this case. As before, the fact that the senior chooses a good candidate whenever at least one is available means that under delegation the candidate is more likely to be good compared to direct recruitment. Delegation continues to be preferred as

$$
\frac{d \widetilde{\Pi}}{d \beta}=\frac{d \widehat{\Pi}_{1}(\beta)}{d \beta}+\partial\left\{\beta \frac{d \bar{\Pi}_{2}\left(s, n_{B}\right)}{d \beta}+(1-\beta) \frac{d \bar{\Pi}_{2}\left(n_{G}, s\right)}{d \beta}+\bar{\Pi}_{2}\left(s, n_{B}\right)-\bar{\Pi}_{2}\left(n_{G}, s\right)\right\}<0
$$

where $\widetilde{\Pi}$ is the aggregate (two period profit) when $s<\underline{n}_{\text {}}$ and $\bar{\Pi}_{2}\left(s, n_{B}\right)$ and $\bar{\Pi}_{2}\left(n_{G}, s\right)$ are the second period profits of the owner with the senior employee and the new recruit in the supervisory position respectively.

Finally suppose that $\vec{n}=p^{2} n_{B}+\left(1-p^{2}\right) n_{G}>s \geq \underline{n_{\rightarrow}}=p(2-p) n_{B}+$ $(1-p)^{2} n_{G}$. Here if the senior chose the good candidate whenever available, the expected type of the candidate would be higher than his own so that he is replaced in a period 1 'pooling-separating equilibrium'. Under these circumstances the only information rent that the senior can possibly claim are its period 1 rents with regard to"type $n$ " and "realization z". There are no "future benefits" from concealing type and the owner would like to offer a 
"fully separating equilibrium". If, instead, he chose a 'bad' candidate whenever available, his own type is higher than the candidate so that he retains his position earning positive (expected) rents from his private information on $z$ in both periods. If the latter rents are larger, i.e.,

$$
q R_{1 G L}+(1-q) R_{1 G H}<(1-q) R_{1 B L}+\delta(1-q) R_{1 B H}
$$

(where $R_{t i j}=w_{t i j}-\left(e_{t}\left(n_{i}, z_{j}\right)\right)^{2}$ is the information rent of thr senior employee in period $t=1,2$ and the candidate's type and the realized value of the additional parameter are $n_{i}$ and $z_{j}$ respectively) the senior employee will clearly choose a 'bad' candidate as long as one is available and a 'fully separating' equilibrium in period 1 cannot be sustained. The owner then makes a 'pooling-separating' contract in period 1 followed by a fully separating contract in period 2. The senior chooses a bad recruit whenever at least one is available and retains his seniority at the end of period 1. The likelyhood that the candidate is 'bad' is higher under delegation, $p(2-p)>p$, means that for $\vec{n}>s>\bar{n}$ when the equilibrium is 'pooling-separating' in period 1 and 'fully separating' in period 2 under both systems, direct recruitment is preferred, since $\frac{d \overbrace{\Pi}}{d \beta}<0$. When $\bar{n}>s>\underline{n}$, direct recruitment is even more preferred by the owner. This is because while the delegation equilibrium remains unaltered the first period equilibrium under direct recruitment is now 'fully separating'.

\section{Tenure - Long Term Contracts}

Carmichael (1988) investigates the question: "Why are less productive older professors not replaced by promising young candidates". He finds that "....tenure is necessary because without it incumbents would never be willing to hire people who might turn out to be better themselves". Although later 
work (Chatterjee and Marshall, 2001) seems to argue that nonverifiability of (academic) output and provision incentives to invest in specialised academic fields have been more important considerations in introducing academic tenure, its role in ensuring quality in academic recruitment must surely have been significant.

In this section we intend to investigate the consequences of tenure which in our context means assuning the manegerial/supervisory position to the senior employee in period 2 even if the new recruit is found to be more capable. We examine whether (1) 'tenured' contracts are always preferred by the principle to untenured contracts, and (2) specifically, whether delegating recruitment accompanied by tenure can do better than direct recruitment when moral hazard is present.

Note that while long term contracts usually do better than short term contracts in similar Principal-Agent models, the way 'tenure' is modelled is not a fully long term contract in the proper sense. This is because in our model we do not think of the Principal's contract offer being conditional on the type of the recruit. An important justification for this may be that the 'type' or 'ability' of the recruit - while observable to the senior employee and eventually to the owner from her observation of period 1 output - may not be verifiable by third parties.

Proposition 3 When the only asymmetric information is regarding the type of the candidate and the senior employee can commit to a long term contract or tenure for the senior employee:

1. The tenured (long term) contract is a two period replica of the one period separating contract. 
2. when the senior has a higher type than expected post recruitment type of the candidates under both systems, i.e., $s>\widetilde{n}$ (where as in Proposition $\left.1 \tilde{n}=p^{2} n_{B}+\left(1-p^{2}\right) n_{G}\right)$ the owner delegates recruitment along with an offers of tenure to the senior.

3. However, if $\widetilde{n}>s$ recruitment will be delegated without the accompanying tenure offer.

Proof: First, observe that in the case of perfectly correlated types, the solution to a long-term (multiperiod) contract is just the replication of the one-period contract [Baron and Besanko(1984,1987), Baron(1989)].

Check from equation (..) above that in the case of the static optimal separating contract the profits of the owner are decreasing in the probability of the bad type, ie $\frac{d \widehat{\Pi}(\beta)}{d \beta}<0$. Since the long term contract is simply a replica of the one period contract, it is obvious that $\frac{d(1+\partial) \widehat{\Pi}(\beta)}{d \beta}<0$. Finally since the probability of the bad type is higher under direct than delegated recruitment $1>p>p^{2}$, delegation of recruitment is clearly preferable. Recall also (Proposition 1) that delegation is always preferable when the short term (untenured) contract is the only option. One consequence is that (in the absence of moral hazard) the expected type of the recruit is $\widetilde{n}$ $=p^{2} n_{B}+\left(1-p^{2}\right) n_{G}$

When $s>\widetilde{n}$, observe that the untenured contract yields the owner $\bar{\Pi}\left(p^{2}\right)+\partial \widehat{\Pi}\left(p^{2}\right)$ as the senior always chooses the good candidate and the first period equilibrium is pooling. This is clearly lower than the $(1+\partial) \widehat{\Pi}\left(p^{2}\right)$ that the owner gets under delegation with tenure. When $\widetilde{n}>s$, on the other hand, the first period equilibrium for the untenured contract is separating and yields $\widehat{\Pi}\left(p^{2}\right)+\Pi^{*}\left(p^{2}\right)$ which is always greater than $(1+\partial) \widehat{\Pi}\left(p^{2}\right)$ so that the owner would never offer tenure. 
Clearly, as there is no moral hazard in recruitment in this case, tenure is not required to mitigate the problem associated with delegation. However, tenure may still be sometimes preferred by the owner to induce the senior employee to reveal the type of his new recruit in period 1 so that the owner may obtain appropriate benefits of this capability. By contrast, with asymmetric information regarding both $\mathrm{n}$ and $\mathrm{z}$, Proposition (2) shows that there may be moral hazard in recruitment. The following proposition confirms that such moral hazard can be mitigated by offering tenure to the senior employee.

Proposition 4 When there is asymmetric information regarding both the candidate type and the periodwise independent random parameter and the owner can commit to tenure for the senior employee:

1. The period 1 component of the tenured (long term) contract is the one period fully separating contract while the period 2 component is conditional on the realized value of $z$ and thus separating only in type.

2. if the senior's type is higher than the expected type of the best available candidate, i.e., $\left.s>\vec{n}=p^{2} n_{B}+\left(1-p^{2}\right) n_{G}\right)$ the owner delegates recruitment with an offer of tenure to the senior.

3. if the senior's type is lower than the expected type of the worst available candidate, i.e., $s<\underline{n}_{\rightarrow}=p(2-p) n_{B}+(1-p)^{2} n_{G}$ recruitment will be delegated without the tenure offer.

4. Finally if $\vec{n}>s>\underline{n}$, the owner will prefer to delegate recruitment along with an offer of tenure. 
Proof: It is well known (Baron and Besanko,1984) that the long term contract is a 2 period replica of the one period (second best) contract when the 'type' is perfectly correlated. If $z$ is periodwise independent the period 1 contract continues to be the same while period 2 conract is just the first best contract . As the senior does not know realized value of $z$ in period 2 at the time of contracting, he cannot obtain any information rents on its account.

In case of $s>\vec{n}$, clearly the best available candidate is selected and the senior retains his position under delegation whether or not there is tenure. However, under a pooling -separating contract with tenure in period 1, the effort of the senior with the good candidate will be suboptimal unlike in the fully separating first period contact with tenure. Further, in period 2, the tenured contract involves information rents only on 'type' while in the untenured version there are rents on $\mathrm{z}$ as well. Thus the tenured contract is preferable.

When $s<\underline{n}$, again with delegation with or without tenure the best available candidate is selected (because even by choosing the worst the senior cannot retain his seniority). However under tenure the senior retains his position while without tenure the best available candidate obtains seniority in period 2. Futher, while the period 1 contract is fully separating (and therefore equivalent) under both systems, the period 2 contract with tenure permits information rents with respect to type (but not $z$ ); by contrast the one without tenure permits information rents with respect to $z$ (but not type). It is easy to check that since a higher output is worth more to the owner than the information rent for 'type', the untenured contract is preferable in this case

Finally, when $\vec{n}>s>\underline{n}$, we have two cases. First, if 


$$
q R_{1 G L}+(1-q) R_{1 G H}>(1-q) R_{1 B L}+\delta(1-q) R_{1 B H}
$$

the untenured contract leads to situation identical to $s>\vec{n}$ where the best possible candidate is chosen regardless of the recruitment method and delegation is favored. The owner in this case will favor tenure. However, if

$$
q R_{1 G L}+(1-q) R_{1 G H}<(1-q) R_{1 B L}+\delta(1-q) R_{1 B H}
$$

the best option in the absence of tenure is direct recuitment. The worst available candidate is selected and there is pooling-separating equilibrium in period 1 and the senior retains his position; the period 2 contract is fully separating with information rents both on 'type' and z. With tenure, the best available candidate is selected so that the expected period 1 output is higher. Further, the senior continues to retain his position in period 2 under both arrangements so that expected period 2 output under tenure is higher as well. Finally, while the untenured contract concedes information rents to the senior for his private observation of the period 2 realization of ' $\mathrm{z}$ ', such rents are eliminated in the tenured contract. Thus, when $\vec{n}>s>\underline{n}$, the owner would always favor delegation with tenure. $\uparrow$

\section{Conclusion}

Our study would appear to suggest that moral hazard in delegating recruitment is unlikely to be a major problem in the case of large corporations with dedicated personnel divisions, and offering tenure on this grounds is unnecessary. Small firms, however, may be vulnerable to such moral hazard when senior employees and line managers with multiple responsibilities are delegated the task of recruitment. When it does occur at all offering tenure to the recruiter would usually be adequate to ensure that bad candidates are not recruited. When the option of tenure is not common or practicable due to various reasons one would expect a greater degree of owner participation 
in recruitment.

While we have carried out our analysis in terms of two available candidates, most of our analysis would go through with a larger number of candidates. The difference would be that the superiority of delegation when the senior chooses the best available candidate (or inferiority in case he chooses the worst available) relative to direct recruitment would tend to become stronger. In other words, delegation would be more likely the larger the number of candidates.

An useful extension to this work would be to examine the role of outside hiring agencies in recruitment. Hiring agencies may be be able to assess candidates reasonably well, though they are unlikely to understand the precise matching of the candidate and the job as well as the line manager. And while they would be likely to be free from the kind of moral hazard problem described above, their services can only be purchased at a price.

\section{References}

[1] Aghion, P. and J. Tirole (1997), "Formal and Real Authority in Organizations", Journal of Political Economy, 105, no 1 :1-29

[2] Armstrong., M. and J. Rochet (1999), "Multidimensional Screening: An User's Guide" , European Economic Review , 43:959-979

[3] Baron, D.P. (1989) "Design of Regulatory Mechanisms and Institutions" in R. Schmalensee and R.D. Willig (ed) Handbook of Industrial Organization, Ch. 14, Elsevier Science

[4] Baron and Besanko (1984), Regulation and Information in a Continuing Relationship, Information Economics and Policy 1, 447-470 
[5] Carroll, Marilyn, Mick Marchington, Jill Earnshaw and Stephen Taylor, "Recruitment in Small Firms", Employee Relations; Volume 21 No. 3; 1999

[6] Carmichael, H. L. (1988). "Incentives in Academics: Why is there Tenure?" Journal of Political Economy, 96,453-72

[7] Chatterjee, K. and R. C. Marshall (2001), "A Model of Acamic Tenure", mimeo

[8] Friebel, G. and Michael Raith (2000). "Abuse of Authority in Hierarchical Communication", mimeo, University of Chicago.

[9] Ghemawat, P and T. Khanna, (1998), "The Nature of Diversified Business Groups: A Research Design and Two Case Studies", Journal of Industrial Economics, vol 46, 1:35-61

[10] Greenwald, B.C., (1986)" Adverse Selection in the Labor Market," Review of Economic Studies, 325-347.

[11] Guesnerie, R and J -J Laffont (1984) "A Complete Solution to a Class of Principal Agent Problems with an Application to the Control of a Self managed Firm", Journal of Public Economics, 25:329-369

[12] Laffont, J -J and J.Tirole (1987). "Comparative Statics of the Optimal Dynamic Incentive Contract" European Economic Review 31: 901-926

[13] Laffont, J -J and J.Tirole (1988)."The Dynamics of Incentive Contracts" Econometrica

[14] Lazear, E and S. Rosen. (1981). "Rank Order Tournaments as Optimal Labour Contracts", Journal of Political Economy, 89, 841-64 
[15] Milgrom, P and J. Roberts (1992). Economics, Organization and Management, New Jersey : Prentice Hall

[16] Spence, A.M..(1973) Market Signalling:Information Transfer in Hiring and Related Processes, Cambridge MA:Harvard University Press

[17] Stewart, J. and V. Knowles (2000), "Graduate Recruitment and Selection Practices in Small Businesses", Career Development, 5:21-38

[18] Williamson,O., M.Wachter and M.Harris, (1975) "Understanding the Employment Relation: An Analysis of Idiosyncratic Exchange" Bell Journal of Economics,6:250-78

\section{Appendix}

Proof of Lemma 1:The First Best Contract: When the type of the candidate is perfectly observable, the problem of the owner in each period is simply to maximize

$$
\Pi_{t}=Y_{t}-w_{t}
$$

subject to the condition that

$$
U_{t} \geq 0
$$

Thus, in the first period, when the manager is the senior employee, or $m_{1}=s$ and the subordinate is the new candidate with perfectly observed type: $l_{1}=n_{i}, i=G, B$ the optimal effort, wages and the respective utlities of the two parties are

$$
\begin{aligned}
e_{1}^{*} & =\frac{s}{2} \\
w_{1}^{*} & =e_{1}^{2}=\frac{s^{2}}{4} \\
U_{1}^{*} & =0
\end{aligned}
$$




$$
\Pi_{1 i}^{*}=s\left(e_{1}+n_{i}\right)-w_{1}=s\left(\frac{s}{4}+n_{i}\right), i=G, B
$$

The Separating Contract (under asymmetric information): Assume now that only the senior employee and not the owner can observe the 'type' of the new candidate(s). This also means that the senior's effort cannot be directly observed (inferred?) by the owner and hence cannot be directly contracted on.

Suppose that the owner offers a pair of separating contracts (outputpayment pairs) $\quad\left[\hat{w}_{i}, \hat{Y}_{i}, i={ }_{B, G}\right]$ in a static(one-period) post-recruitment game. Now, define $\hat{e}\left(n_{i}\right)$ as the effort required by a senior who truthfully reports the 'type' of his candidate to produce the output selected for him by the owner, i.e.,

$$
\hat{e}\left(n_{i}\right): s\left(\hat{e}\left(n_{i}\right)+n_{i}\right)=\hat{Y}_{i} \quad i=G, B
$$

and $e ́\left(n_{B}, n_{G}\right)$ as the effort required by the senior employee with a 'good' recruit $n_{G}$, to produce the output intended for the case where the candidate is bad, $\hat{Y}_{B}$,

$$
\dot{e}\left(n_{B}, n_{G}\right): s\left(\dot{e}\left(n_{B}, n_{G}\right)+n_{G}\right)=s\left(\hat{e}\left(n_{B}\right)+n_{B}\right)=\hat{Y}_{B}
$$

which implies that

$$
\dot{e}\left(n_{B}, n_{G}\right)=\hat{e}\left(n_{B}\right)-n_{G}+n_{B}=\hat{e}\left(n_{B}\right)-\Delta n
$$

The optimal separating wage-effort pair $\left[\hat{w}_{i}, \hat{e}\left(n_{i}\right), i={ }_{B, G}\right] \quad$ underlying such a separating contract $\left[\hat{w}_{i}, \hat{Y}_{i}, i={ }_{B, G}\right]$ must satisfy the standard incentive compatibility condition (for good type):

$$
\hat{w}_{G}-\left(\hat{e}\left(n_{G}\right)\right)^{2} \geq \hat{w}_{B}-\left(\hat{e}\left(n_{B}, n_{G}\right)\right)^{2}=\hat{w}_{B}-\left(\hat{e}\left(n_{B}\right)\right)^{2}+2 \hat{e}\left(n_{B}\right) \Delta n-(\Delta n)^{2}
$$

along with the usual individual rationality contract (for the bad type)

$$
\hat{w}_{B}-\left(\hat{e}\left(n_{B}\right)\right)^{2} \geq 0
$$


The problem of the owner in optimally selecting a pair of separating contracts in this one period post recruitment game is to choose $\left[\hat{w}_{B}, \hat{e}\left(n_{B}\right), \hat{w}_{G}, \hat{e}\left(n_{G}\right)\right]$ to maximize its objective function:

$$
\widehat{\Pi}(\beta)=\beta\left[s\left(\hat{e}\left(n_{B}\right)+n_{B}\right)-\hat{w}_{B}\right]+(1-\beta)\left[s\left(\hat{e}\left(n_{G}\right)+n_{G}\right)-\hat{w}_{G}\right]
$$

subject to the two preceding constraints, where $\beta$ is the probability post recruitment - that the candidate is 'bad'. It is fairly easy to check that the solution to this problem is:

$$
\begin{aligned}
& \hat{e}\left(n_{G}\right)=\frac{s}{2}, \hat{e}\left(n_{B}\right)=\frac{s}{2}-\frac{1-\beta}{\beta} \Delta n \\
& \hat{w}_{G}=\frac{s^{2}}{4}+2\left(\frac{s}{2}-\frac{1-\beta}{\beta} \Delta n\right) \Delta n-(\Delta n)^{2}, \hat{w}_{B}=\left(\frac{s}{2}-\frac{1-\beta}{\beta} \Delta n\right)^{2} \\
& \hat{U}_{G}=2\left(\frac{s}{2}-\frac{1-\beta}{\beta} \Delta n\right) \Delta n-(\Delta n)^{2}, \hat{U}_{B}=0 \\
& \widehat{\Pi}(\beta)=\frac{s^{2}}{4}+s n_{B}+(\Delta n)^{2}\left[\frac{2(2-\beta)}{\beta}-1\right]
\end{aligned}
$$

The Optimal Pooling Contract: Consider now the optimal static pooling contract $[\bar{w}, \bar{Y}]$ that satisfies the individual rationality constraint and hence is always accepted. If we define the effort of the senior employee who has a bad candidate under such a pooling contract as $\bar{e}\left(n_{B}\right)$, where

$$
\bar{e}\left(n_{B}\right): s\left(\bar{e}\left(n_{B}\right)+n_{B}\right)=\bar{Y}
$$

then it must be true that

$$
\bar{w}-\left(\bar{e}\left(n_{B}\right)\right)^{2} \geq 0
$$

Further, to produce the same amount of output the senior employee with the 'good' candidate obviously puts in lower effort

$$
\bar{e}\left(n_{G}\right)=\bar{e}\left(n_{B}\right)-\Delta n
$$

and produces the same output $\bar{Y}$ for the same payment $\bar{w}$. The problem of the owner in choosing an optimal pooling contract, therefore, is to maximize profits :

$$
\bar{\Pi}(\beta)=\beta\left[s\left(\bar{e}\left(n_{B}\right)+n_{B}\right)-\bar{w}\right]+(1-\beta)\left[s\left(s\left(\bar{e}\left(n_{B}\right)-\Delta n+n_{G}\right)-\bar{w}\right]\right.
$$


when the probability of the bad type is $\beta$,subject to the three preceding conditions. It is easy to check that the solution to this problem is given

$$
\begin{aligned}
& \bar{e}\left(n_{B}\right)=\frac{s}{2}, \bar{e}\left(n_{G}\right)=\frac{s}{2}-\Delta n \\
& \bar{w}=\frac{s^{2}}{4} \\
& \bar{U}_{G}=\Delta n(s-\Delta n), \bar{U}_{B}=0 \\
& \bar{\Pi}(\beta)=\frac{s^{2}}{4}+s n_{B}
\end{aligned}
$$

It is easy to check that $\frac{d \widehat{\Pi}}{d \beta}<0, \frac{d \bar{\Pi}}{d \beta}=0$ and $\widehat{\Pi}(\beta)>\bar{\Pi}(\beta)$

\section{Proof of Lemma 3:}

Assume that only the senior employee and not the owner can observe both the 'type' of the candidate(s) as well as the realization of the periodwise independent random parameter $z$ in period 1 . As we have already indicated, $z$ is observed by the senior employee after his recruitment is made.

\section{Optimal Static Separating Contract}

Assume first that the owner offers a set of fully separating contracts (output-payment pairs) $\quad\left[\hat{w}_{B L}, \hat{Y}_{B L}, \hat{w}_{B H}, \hat{Y}_{B H}, \hat{w}_{G L}, \hat{Y}_{G L}, \hat{w}_{G H}, \hat{Y}_{G H}\right]$ in a static(one-period) post-recruitment game. Now, define $\hat{e}\left(n_{i}, z_{j}\right)$ as the effort required by a senior who truthfully reports the 'type' of his candidate to produce the output selected for him by the owner, i.e.,

$$
\hat{e}\left(n_{i}, z_{j}\right): s\left(\hat{e}\left(n_{i}, z_{j}\right)+n_{i}+z_{j}\right)=\hat{Y}_{i j} \quad i=G, B, j=L, H
$$

and $\dot{e}\left(n_{k}, z_{l}, n_{i}, z_{j}\right)$ as the effort required by the senior employee with a recruit $n_{i}$, who has observed a realization of the random parameter $z_{j}$ to produce the output intended for the case where the candidate is of type $n_{k}$ and the realization of the random parameter $z_{l}, \hat{Y}_{k l}$.

$\dot{e}\left(n_{k}, z_{l}, n_{i}, z_{j}\right): s\left(\hat{e}\left(n_{k}, z_{l}, n_{i}, z_{j}\right)+n_{i}+z_{j}\right)=s\left(\hat{e}\left(n_{k}, z_{l}\right)+n_{k}+z_{l}\right)=\hat{Y}_{k l}$

which implies that

$\hat{e}\left(n_{k}, z_{l}, n_{i}, z_{j}\right)=\hat{e}\left(n_{k}, z_{l}\right)-\left(n_{i}-n_{k}\right)-\left(z_{j}-z_{l}\right)$ 
The optimal menu $\left[\left\{\hat{w}_{i j}, \hat{e}\left(n_{i}, z_{j}\right)\right\}, i={ }_{B, G}, j={ }_{L, H}\right]$ underlying such a separating mechanism $\left[\hat{w}_{i j}, \hat{Y}_{i j}, i={ }_{B, G}, j={ }_{L, H}\right]$ must satisfy the 'downward'incentive compatibility conditions

$$
\begin{aligned}
& \hat{w}_{G L}-\left(\hat{e}\left(n_{G}, z_{L}\right)\right)^{2} \geq \hat{w}_{B L}-\left(\hat{e}\left(n_{B}, z_{L}, n_{G}, z_{L}\right)\right)^{2} \\
& =\hat{w}_{B L}-\left(\hat{e}\left(n_{B}, z_{L}\right)\right)^{2}+2 \hat{e}\left(n_{B}, z_{L}\right) \Delta n-(\Delta n)^{2} \\
& \hat{w}_{B H}-\left(\hat{e}\left(n_{B}, z_{H}\right)\right)^{2} \geq \hat{w}_{B L}-\left(\hat{e}\left(n_{B}, z_{L}, n_{B}, z_{H}\right)\right)^{2} \\
& =\hat{w}_{B L}-\left(\hat{e}\left(n_{B}, z_{L}\right)\right)^{2}+2 \hat{e}\left(n_{B}, z_{L}\right) \Delta z-(\Delta z)^{2} \\
& \hat{w}_{G H}-\left(\hat{e}\left(n_{G}, z_{H}\right)\right)^{2} \geq \\
& \max \left\{\hat{w}_{B L}-\left(\dot{e}\left(n_{B}, z_{L}, n_{G}, z_{H}\right)\right)^{2}, \hat{w}_{G L}-\left(\dot{e}\left(n_{G}, z_{L}, n_{G}, z_{H}\right)\right)^{2},\right. \\
& \left.\hat{w}_{B H}-\left(\dot{e}\left(n_{B}, z_{H}, n_{G}, z_{H}\right)\right)^{2}\right\}
\end{aligned}
$$

along with the usual individual rationality contract (for 'bad-low' type)

$$
\hat{w}_{B L}-\left(\hat{e}\left(n_{B}, z_{L}\right)\right)^{2} \geq 0
$$

The problem of the owner in devising an optimal (static) separating contract, therefore, is the one of maximizing

$$
\begin{aligned}
& \widehat{\widehat{\Pi}}(\beta)=\beta\left[q\left\{s\left(\widehat{e}\left(n_{B}, z_{L}\right)+n_{B}+z_{L}\right)-\widehat{w}_{B L}\right\}\right. \\
&+(1-q)\left\{s\left(\widehat{e}\left(n_{B}, z_{H}\right)+n_{B}+z_{H}\right)-\widehat{w}_{B H}\right\} \\
&+(1-\beta)\left[q\left\{s\left(\widehat{e}\left(n_{G}, z_{L}\right)+n_{G}+z_{L}\right)-\widehat{w}_{G L}\right\}\right. \\
& \quad+(1-q)\left\{s\left(\widehat{e}\left(n_{G}, z_{H}\right)+n_{G}+z_{H}\right)-\widehat{w}_{G H}\right\}
\end{aligned}
$$

where $\beta$ is the probability that the candidate is bad, subject to the preceding constraints. The incentive constraints above are the downward incentive constraints on the 'good-low' and 'bad-high' types as well as the downward incentive constraint on the 'good-high' type which must ensure that it does not mimic either of 'bad-low','good-low' and 'bad-high'. Regarding the last three it is easy to check that if either of the last two is satisfied then so is the first. Consequently, the first expression in constraint [3] drops out (is not binding). Given the information rents obtainable by the 'good-low' and the 'bad-high' types, the rent obtained by the 'good-high' 
type is given by

$$
\begin{aligned}
\hat{w}_{G H}-\left(\hat{e}\left(n_{G}, z_{H}\right)\right)^{2} \geq \\
\max \left\{\hat{w}_{G L}-\left(\dot{e}\left(n_{G}, z_{L}, n_{G}, z_{H}\right)\right)^{2}, \hat{w}_{B H}-\left(\dot{e}\left(n_{B}, z_{H}, n_{G}, z_{H}\right)\right)^{2}\right\} \\
=\max \left\{2 e\left(n_{B}, z_{L}\right) \Delta n+2 e\left(n_{G}, z_{L}\right) \Delta z, 2 e\left(n_{B}, z_{L}\right) \Delta z+2 e\left(n_{B}, z_{H}\right) \Delta n\right\} \\
-(\Delta n)^{2}-(\Delta z)^{2}
\end{aligned}
$$

If the first term under parentheses is larger (i.e the information rents of the 'good-high' type required to meet its incentive constraints with the 'good-low' type are higher than the one required to meet its incentive constraints with respect to the 'bad-high' type), then the third incentive constraint takes the form

$$
\hat{w}_{G H}-\left(\hat{e}\left(n_{G}, z_{H}\right)\right)^{2} \geq 2 e\left(n_{B}, z_{L}\right) \Delta n+2 e\left(n_{G}, z_{L}\right) \Delta z-(\Delta n)^{2}-(\Delta z)^{2}
$$

Solving for the optimal effort levels we obtain

$$
\begin{aligned}
& \hat{e}\left(n_{G}, z_{H}\right)=\frac{s}{2}, \quad \hat{e}\left(n_{B}, z_{H}\right)=\frac{s}{2}, \quad \hat{e}\left(n_{G}, z_{L}\right)=\frac{s}{2}-\frac{1-q}{p} \Delta z, \\
& \hat{e}\left(n_{B}, z_{H}\right)=\frac{s}{2}-\frac{(1-q) \Delta z}{q}-\frac{(1-\beta) \Delta n}{\beta q}
\end{aligned}
$$

Similarly, if the the information rents of the 'good-high' type required to meet its incentive constraints with the 'bad-high' type are higher we get

$$
\begin{aligned}
& \hat{e}\left(n_{G}, z_{H}\right)=\frac{s}{2}, \quad \hat{e}\left(n_{B}, z_{H}\right)=\frac{s}{2}-\frac{1-\beta}{\beta} \Delta n, \quad \hat{e}\left(n_{G}, z_{L}\right)=\frac{s}{2}, \\
& \hat{e}\left(n_{B}, z_{H}\right)=\frac{s}{2}-\frac{(1-\beta) \Delta n}{\beta}-\frac{(1-q) \Delta z}{\beta q}
\end{aligned}
$$

Substituting these values into the objective function, the profit of the owner can be reduced to the form:

$$
\widehat{\widehat{\Pi}}(\beta)=\frac{s^{2}}{4}+s n_{B}+s z_{L}+\frac{1-q}{q}(\Delta z)+K(\beta), \text { where } K(\beta)>0 \text { and } \frac{d K}{d \beta}<0
$$

\section{Optimal Static Contract Pooling -cum- Separating Contract}

Consider now the optimal static contract $\left[\bar{w}_{L}, \bar{Y}_{L}, \bar{w}_{H}, \bar{Y}_{H}\right]$ pooling in types but separating in the periodwise uncorrelated random parameter $z$. Define the effort of the senior employee with a candidate of type $n_{B}$ and a low realization of $z$ under such a contract as $\bar{e}\left(n_{B}, z_{L}\right)$, where 
$\bar{e}\left(n_{B}, z_{L}\right): s\left(\bar{e}\left(n_{B}, z_{L}\right)+n_{B}+z_{L}\right)=\bar{Y}_{L}$

then it must be true that

$\bar{w}_{L}-\left(\bar{e}\left(n_{B}, z_{L}\right)\right)^{2} \geq 0$

Further, to produce the same amount of output the senior employee with the same low realization but a better candidate $n_{G}$ with obviously puts in lower effort

$\bar{e}\left(n_{G}, z_{L}\right)=\bar{e}\left(n_{B}, z_{L}\right)-\Delta n$

and produces the same output $\bar{Y}_{L}$ for the same payment $\bar{w}_{L}$.

The contract is however separating in the additional parameter $z$ so that it involves higher output and payments for the senior employee with the bad candidate who has observed $z_{H}$. As usual this is given by

$$
\begin{gathered}
\bar{w}_{H}-\left(\bar{e}\left(n_{B}, z_{H}\right)\right)^{2} \geq \bar{w}_{L}-\left(\bar{e}\left(n_{B}, z_{L}\right)\right)^{2}+2\left(\bar{e}\left(n_{B}, z_{L}\right)\right) \Delta z-\Delta z^{2} \\
=2\left(\bar{e}\left(n_{B}, z_{L}\right)\right) \Delta z-\Delta z^{2}
\end{gathered}
$$

The senior with the good recruit but the same high realization of $z$ is paid the same $\bar{w}_{H}$ but puts in lower effort

$\bar{e}\left(n_{G}, z_{H}\right)=\bar{e}\left(n_{B}, z_{H}\right)-\Delta n$

The problem of the owner then is to maximize profits :

$$
\begin{aligned}
& \overline{\bar{\Pi}}(\beta)=q\{\beta[s(\left.\left.\bar{e}\left(n_{B}, z_{L}\right)+n_{B}+z_{L}\right)-\bar{w}_{L}\right] \\
&\left.+(1-\beta)\left[s\left(\bar{e}\left(n_{B}, z_{L}\right)-\Delta n+n_{G}+z_{L}\right)-\bar{w}_{L}\right]\right\} \\
&+(1-q)\left\{\beta\left[s\left(\bar{e}\left(n_{B}, z_{H}\right)+n_{B}+z_{H}\right)-\bar{w}_{H}\right]\right. \\
&\left.+(1-\beta)\left[s\left(\bar{e}\left(n_{B}, z_{H}\right)-\Delta n+n_{G}+z_{H}\right)-\bar{w}_{H}\right]\right\} \\
&=q\left[s\left(\bar{e}\left(n_{B}, z_{L}\right)+n_{B}+z_{L}\right)-\bar{w}_{L}\right]+(1-q)\left[s\left(\bar{e}\left(n_{B}, z_{H}\right)+n_{B}+z_{H}\right)-\bar{w}_{H}\right]
\end{aligned}
$$

when the probability of the bad type is $\beta$,subject to the three preceding conditions. It is easy to check that the solution to this problem is given by 


$$
\begin{aligned}
& \bar{e}\left(n_{B}, z_{L}\right)=\frac{s}{2}-\frac{(1-q)}{q} \Delta z, \bar{e}\left(n_{G}, z_{L}\right)=\frac{s}{2}-\Delta n, \bar{e}\left(n_{B}, z_{H}\right)=\frac{s}{2}, \\
& \bar{e}\left(n_{G}, z_{H}\right)=\frac{s}{2}-\Delta n \\
& \bar{w}_{L}=\left(\frac{s}{2}-\frac{(1-q)}{q} \Delta z\right)^{2}, \bar{w}_{H}=\frac{s^{2}}{4}+2\left(\frac{s}{2}-\frac{(1-q)}{q} \Delta z\right) \Delta z-(\Delta z)^{2} \\
& \overline{\bar{\Pi}}(\beta)=\frac{s^{2}}{4}+s n_{B}+s z_{L}+\frac{1-q}{q}(\Delta z)
\end{aligned}
$$

From these it may be checked that $\frac{d \widehat{\hat{\Pi}}}{d \beta}<0, \frac{d \overline{\bar{\Pi}}}{d \beta}=0 \quad$ and $\widehat{\widehat{\Pi}}(\beta)>\overline{\bar{\Pi}}(\beta)$ 
Time Sequence For Game With Asymmetric Information Only With Regard To Candidate Type

1. senior observes ' $n$ '

2. owner selects recruitment mode

(direct/delegated) and offers period 1 contract

3. senior accepts/rejects contract

4. owner/senior selects candidate

5. senior selects effort

6. period 1 output realized and payments made

7. owner retains/downgrades senior (only shortterm contract)

8. owner makes period 2 offer

9. period 2 manager selects effort

10. period 1 output realized and payments made

Figure 1 
Time Sequence For Game With Additional Asymmetric Information

1. senior observes ' $n$ ' and $z_{1}$

2. owner selects recruitment mode direct/deleg and offers period 1 contract

3. senior accepts/rejects contract

4. owner/senior selects candidate

5. senior selects effort

6. period 1 output realized and payments made

7. owner retains/downgrades senior (only shortterm contract)

8. manager observes $z_{2}$

9. owner offers period 2 contract

10. period 2 manager selects effort

11. period 2 output realized and payments made

Figure 2 


\section{CESifo Working Paper Series}

(for full list see www.cesifo.de)

743 Robert Fenge, Silke Uebelmesser, and Martin Werding, Second-best Properties of Implicit Social Security Taxes: Theory and Evidence, June 2002

744 Wendell Fleming and Jerome Stein, Stochastic Optimal Control, International Finance and Debt, June 2002

745 Gene M. Grossman, The Distribution of Talent and the Pattern and Consequences of International Trade, June 2002

746 Oleksiy Ivaschenko, Growth and Inequality: Evidence from Transitional Economies, June 2002

747 Burkhard Heer, Should Unemployment Benefits be Related to Previous Earnings?, July 2002

748 Bas van Aarle, Giovanni Di Bartolomeo, Jacob Engwerda, and Joseph Plasmans, Staying Together or Breaking Apart: Policy-makers' Endogenous Coalitions Formation in the European Economic and Monetary Union, July 2002

749 Hans Gersbach, Democratic Mechanisms: Double Majority Rules and Flexible Agenda Costs, July 2002

750 Bruno S. Frey and Stephan Meier, Pro-Social Behavior, Reciprocity or Both?, July 2002

751 Jonas Agell and Helge Bennmarker, Wage Policy and Endogenous Wage Rigidity: A Representative View From the Inside, July 2002

752 Edward Castronova, On Virtual Economies, July 2002

753 Rebecca M. Blank, U.S. Welfare Reform: What's Relevant for Europe?, July 2002

754 Ruslan Lukach and Joseph Plasmans, Measuring Knowledge Spillovers Using Patent Citations: Evidence from the Belgian Firm's Data, July 2002

755 Aaron Tornell and Frank Westermann, Boom-Bust Cycles in Middle Income Countries: Facts and Explanation, July 2002

756 Jan K. Brueckner, Internalization of Airport Congestion: A Network Analysis, July 2002

757 Lawrence M. Kahn, The Impact of Wage-Setting Institutions on the Incidence of Public Employment in the OECD: 1960-98, July 2002

758 Sijbren Cnossen, Tax Policy in the European Union, August 2002

759 Chandima Mendis, External Shocks and Banking Crises in Developing Countries: Does the Exchange Rate Regime Matter?, August 2002 
760 Bruno S. Frey and Lars P. Feld, Deterrence and Morale in Taxation: An Empirical Analysis, August 2002

761 Lars Calmfors and Åsa Johansson, Nominal Wage Flexibility, Wage Indexation and Monetary Union, August 2002

762 Alexander R. W. Robson and Stergios Skaperdas, Costly Enforcement of Property Rights and the Coase Theorem, August 2002

763 Horst Raff, Preferential Trade Agreements and Tax Competition for Foreign Direct Investment, August 2002

764 Alex Cukierman and V. Anton Muscatelli, Do Central Banks have Precautionary Demands for Expansions and for Price Stability? - Theory and Evidence, August 2002

765 Giovanni Peri, Knowledge Flows and Knowledge Externalities, August 2002

766 Daniel Friedman and Nirvikar Singh, Equilibrium Vengeance, August 2002

767 Sam Bucovetsky and Michael Smart, The Efficiency Consequences of Local Revenue Equalization: Tax Competition and Tax Distortions, August 2002

768 Tapio Palokangas, International Labour Market Regulation and Economic Growth with Creative Destruction, August 2002

769 Rudi Dornbusch, The New International Architecture, September 2002

770 Hans-Werner Sinn, Weber's Law and the Biological Evolution of Risk Preferences: The Selective Dominance of the Logarithmic Utility Function, September 2002

771 Thomas Mayer, The Macroeconomic Loss Function: A Critical Note, September 2002

772 Seppo Honkapohja and Kaushik Mitra, Learning Stability in Economies with Heterogenous Agents, September 2002

773 David Laidler, Inflation Targets Versus International Monetary Integration - A Canadian Perspective, September 2002

774 Morten I. Lau, Panu Poutvaara, and Andreas Wagener, The Dynamic Cost of the Draft, September 2002

775 Steven Brakman, Harry Garretsen, and Charles van Marrewijk, Locational Competition and Agglomeration: The Role of Government Spending, September 2002

776 Anke S. Kessler and Christoph Lülfesmann, The Theory of Human Capital Revisited: On the Interaction of General and Specific Investments, September 2002

777 Kjell Erik Lommerud, Frode Meland and Lars Sørgard, Unionized Oligopoly, Trade Liberalization and Location Choice, September 2002 
778 Antonio Merlo and François Ortalo-Magné, Bargaining over Residential Real Estate: Evidence from England, September 2002

$779 \mathrm{Yu}-\mathrm{Fu}$ Chen and Michael Funke, Exchange Rate Uncertainty and Labour Market Adjustment under Fixed and Flexible Exchange Rates, September 2002

780 Michael S. Michael, International Migration, Income Taxes and Transfers: A Welfare Analysis, September 2002

781 Clemens Fuest and Alfons Weichenrieder, Tax Competition and Profit Shifting: On the Relationship between Personal and Corporate Tax Rates, October 2002

782 Jan Bouckaert and Hans Degryse, Softening Competition by Enhancing Entry: An Example from the Banking Industry, October 2002

783 Johann K. Brunner and Susanne Pech, Adverse Selection in the Annuity Market with Sequential and Simultaneous Insurance Demand, October 2002

784 Gregory D. Hess and Eduard Pelz, The Economic Welfare Cost of Conflict: An Empirical Assessment, October 2002

785 Jan Erik Askildsen, Uwe Jirjahn, and Stephen C. Smith, Works Councils and Environmental Investment: Theory and Evidence from German Panel Data, October 2002

786 Geir H. Bjønnes, Dagfinn Rime, and Haakon O. Aa. Solheim, Volume and Volatility in the FX-Market: Does it matter who you are?, October 2002

787 John Evans and John Fingleton, Entry Regulation and the Influence of an Incumbent Special Interest Group, October 2002

788 Wolfgang Ochel, International Comparisons and Transfer of Labour Market Institutions, October 2002

789 B. Gabriela Mundaca, Moral Hazard Effects of Bailing out under Asymmetric Information, October 2002

790 Gene M. Grossman and Edwin L.-C. Lai, International Protection of Intellectual Property, October 2002

791 John Hassler, José V. Rodriguez Mora, Kjetil Storesletten, and Fabrizio Zilibotti, A Positive Theory of Geographic Mobility and Social Insurance, October 2002

792 Paul De Grauwe and Marianna Grimaldi, The Exchange Rate in a Model with Heterogeneous Agents and Transactions Costs, October 2002

793 Guido Friebel and Mariassunta Giannetti, Fighting for Talent: Risk-shifting, Corporate Volatility, and Organizational Change, October 2002 
794 Jan Erik Askildsen, Badi H. Baltagi, and Tor Helge Holmås, Will Increased Wages Reduce Shortage of Nurses? A Panel Data Analysis of Nurses' Labour Supply, October 2002

795 Marko Köthenbürger and Panu Poutvaara, Social Security Reform and Intergenerational Trade: Is there Scope for a Pareto-Improvement?, October 2002

796 Paul De Grauwe and Laura Rinaldi, A Model of the Card Payment System and the Interchange Fee, October 2002

797 Volker Böhm and Tomoo Kikuchi, Dynamics of Endogenous Business Cycles and Exchange Rate Volatility, October 2002

798 Mariam Camarero, Javier Ordóñez, and Cecilio Tamarit, The Euro-Dollar Exchange Rate: Is it Fundamental?, October 2002

799 Misa Tanaka, How Do Bank Capital and Capital Adequacy Regulation Affect the Monetary Transmission Mechanism?, October 2002

800 Jörg Baten and Andrea Wagner, Autarchy, Market Disintegration, and Health: The Mortality and Nutritional Crisis in Nazi Germany, 1933-1937, October 2002

801 Saku Aura, Uncommitted Couples: Some Efficiency and Policy Implications of Marital Bargaining, October 2002

802 Wolfram F. Richter, Delaying Integration of Immigrant Labor for the Purpose of Taxation, October 2002

803 Gil S. Epstein and Shmuel Nitzan, The Politics of Randomness, October 2002

804 John Hassler and José V. Rodriguez Mora, Should UI Benefits Really Fall over Time?, October 2002

805 Friedrich Breyer and Stefan Felder, The Dead-anyway Effect Revis(it)ed, October 2002

806 Assar Lindbeck and Solveig Wikström, E-exchange and the Boundary between Households and Organizations, November 2002

807 Dieter Bös, Contests Among Bureaucrats, November 2002

808 Steven Brakman, Harry Garretsen, and Marc Schramm, The Strategic Bombing of German Cities during World War II and its Impact on City Growth, November 2002

809 Florian Englmaier and Achim Wambach, Contracts and Inequity Aversion, November 2002

810 Sarbajit Sengupta, Delegating Recruitment under Asymmetric Information, December 2002 